\title{
Estimação Bayesiana das Medidas do Desempenho da Colpocitologia Oncológica, Captura Hibrida II e Inspeçãa Visual com Ácido Acético em Detectar Lesōes Cervicais Pré-neoplásicas e Neoplásicas
}

\author{
Bayesian Estimation of the Performance of Cervical Cytology, Hybrid Capture II and Visual \\ Inspection with Acetic Acid in to Detect Cervical Intraepithelial Neoplasia
}

Autor: Edson Zangiacomi Martinez

Orientador: Prof. Dr. Francisco Louzada-Neto

Tese de Doutorado apresentada ao Curso de Pós Graduação da Faculdade de Ciências Médicas da Universidade Estadual de Campinas para obtenção do título de Doutor em Tocoginecologia, em 27 de novembro de 2003.

O objetivo deste estudo foi obter estimativas Bayesianas das medidas do desempenho da colpocitologia oncológica (CO), captura híbrida II (CH II) e inspeção visual com ácido acético (IVA) em detectar isoladamente lesões cervicais pré neoplásicas, desconsiderando a existência de um teste de referência (padrão ouro). Participaram do estudo 1.195 mulheres atendidas no Centro de Saúde Santa Bárbara, Campinas, e 221 mulheres atendidas no CAISM (Centro de Atenção Integral à Saúde da Mulher) em 2002. As estimativas Bayesianas das sensibilidades da CO, IVA e $\mathrm{CH}$ II foram, respectivamente, 53,6, 52,9 e 90,3\%, enquanto as especificidades foram estimadas em, respectivamente, 97,0, 93,0 e 88,7\%. O método Bayesiano estimou a prevalência de lesões precursoras do câncer cervical em 6,4\%. Como uma alternativa de análise, estas mesmas medidas foram estimadas por um método clássico, por máxima verossimilhança. O método clássico estimou as sensibilidades da CO, IVA e $\mathrm{CH}$ II em, respectivamente, 43,3, 31,5 e 89,0\%, e as especificidades em, respectivamente, 97,4, 94,9 e 90,9\%. A prevalência de lesões precursoras foi estimada em $9 \%$, pelo método clássico. Foi proposta uma extensão do modelo Bayesiano empregado neste trabalho, prevendo a inclusão de covariáveis. Este novo modelo mostrou-se uma eficiente alternativa para a obtenção de medidas de desempenho quando um padrão ouro não é disponível. O modelo incluiu as covariáveis idade e gravidez, mostrando evidências de que a prevalência de lesões estaria associada à idade. $\mathrm{O}$ modelo mostrou também evidências de que a sensibilidade e a especificidade da IVA são menores para as mulheres mais jovens.

Palavras-chave: Colo uterino: câncer. Colpocitologia oncológica. Captura híbrida. Inspeção visual com ácido acético.

Keywords: Cervical cancer. Cervical cytology. Hybrid capture. Visual inspection.

Colpopexia Sacroespinhal: Análise de sua Aplicação em Portadoras de Prolapso Uterovaginal e de Cúpula Vaginal Pós-histerectomia

\section{Sacrospinal Colpopexy: Analysis of its Application to Patients with Uterovaginal and Vaginal Dome Prolapse After Hysterectomy}

Autor: Octacílio Figueirêdo Netto

Orientador: Prof. Dr. José Rafael Macéa

Tese de Doutorado apresentada ao Curso de Pós-Graduação da Faculdade de Ciências Médicas da Santa Casa de São Paulo, para obtenção do Título de Doutor em Medicina, em 19 de Dezembro de 2003.

Objetivo: desenvolveu-se uma variante técnica de colpopexia sacroespinhal para tratamento cirúrgico do prolapso de cúpula pós-histerectomia, e também como medida adjuvante nos casos de prolapso uterovaginal total, visando facilitar o procedimento e estimular sua maior utilização no nosso meio.

Método: quarenta e seis pacientes foram operadas e acompanhadas por um período de 12 a 44 meses, com média de 32 meses. Vinte e três pacientes apresentavam prolapso de cúpula vaginal (grupo A), e 23 eram portadoras de prolapso uterovaginal total (grupo B). Os resultados obtidos em ambos os grupos foram comparados. O método utilizado obedece a princípios anatômicos bem definidos, e difere da técnica original pelo emprego de um porta-agulha curvo orientado de cima para baixo para transfixar o ligamento sacro- 